\title{
Харабаева В.И. \\ Лексико-семантические группы глаголов со значением каузации контакта объектов и посессивных отношений
}

Сибирское отделение Российской академии наук (Россия, Якутск)

doi: $10.18411 / l j-08-2021-99$

\section{Аннотация}

Классификация глаголов по лексико-семантическим группам позволяет более полно осветить содержательные стороны глаголов. Статья раскрывает особенности семантической классификации глаголов с семантикой каузации контакта объектов и посессивных отношений на материале якутского языка. Глагольные лексемы с общей семантикой каузации контакта объектов и посессивных отношений объектов распадаются на микрогруппы по различным значениям. Глаголы со значением каузации контакта объектов имеют следующие значения: а) связывать кого-либо с кем-либо, б) связывать что-либо с чем-либо, в) соединяться с кем-либо, чем-либо. Глаголы со значением причинности притяжательных отношений обозначают два основных значения: а) привязанность к независимому объекту, б) привязанность к объекту, принадлежащему другому лицу (лицам).

Ключевые слова: глагол, семантика, лексическое значение слова, лексикосемантические группы, действие, каузация контакта объектов, посессивные отношения.

\section{Abstract}

Classification of verbs by lexical and semantic groups allows you to more fully illuminate the content of the verbs. The article reveals the features of the semantic classification of verbs with the semantics of causation of contact of objects and possessive relations on the material of the Yakut language. Verb lexemes with the general semantics of causation of object contact and possessive relations of objects fall into microgroups according to different meanings. Verbs with the meaning of causation of contact of objects have the following meanings: a) connect someone with someone, b) connect something with something, c) connect with someone, something. Verbs with the meaning of the causation of possessive relations denote two main meanings: a) the attachment of an independent object, b) the attachment of an object belonging to another person (s).

Keywords: verb, semantics, lexical meaning of a word, lexical-semantic groups, action, causation of contact of objects, possessive relations.

Основными критериями, объединяющими лексические единицы в одно поле, нужно считать «общность значений», «смысловой признак», «семантический признак». Ряд исследователей термин «семантическое поле» используют в отношении более узких лингвистических терминов (ЛСГ (далее- лексико-семантическая группа), синонимический ряд и т.п.), или же эти обозначения употребляются как терминологические синонимы. По мнению большинства исследователей суть заключается в том, что ЛСГ - это составная единица лексической системы, выделяемая на лингвистической и лингвологической основе, члены которой связаны на основе сходства, противоположности и иерархии, «а, конкретнее - это совокупность слов, относящихся к одной и той же части речи, объединенных помимо грамматических сем, еще общей категориально-лексической семой (архисемой, классемой), которая является основной и существенной при выделении слов в одну ЛСГ» [5, с. 31].

В русском языке Т. А. Потапенко в семантическом поле глаголов конкретного действия, направленного на объект, делит на ряд конкретных ЛСГ: глаголов обработки, соединения, разъединения, уничтожения, повреждения, извлечения, исправления, 
перемешивания и некоторых других [3]. Т. А. Кильдибекова в семантическом поле глаголов действия выделила следующие ЛСГ: глаголы созидания объектов, каузации контакта предметов, каузации функтивных отношений, локализации и каузации перемещения объектов, каузации посессивных отношений [1]. В данной статье рассмотрим ЛСГ глаголов собственно действия со значением каузации контакта объектов и посессивных отношений.

Глаголов действия со значением каузации контакта объектов «обозначают ситуации, в которых различного рода связи, соотношения объектов создают целое из отдельных частей» [4, с. 118] и т.д. Типовая семантика: соединять кого-либо с кемлибо, что-либо с чем-либо, соединяться с кем-, чем-либо. Общее значение класса выражается в глаголах холбоо- 'соединить; объединить', т.е. 'соединить, установить связь, общение, близость с кем-, чем-либо', хомуй- собрать, cblhblap- 'прикрепить'.

ЛСГ глаголов данной семантики образует отдельные микрогруппы:

1. Глаголы со значением 'скрепить, связать одно с другим'. Баай- 1. 'привязывать, подвязывать' (колокольчигы дугађа баай 'подвязать колокольчик к дуге'); 2. 'привязывать, прикреплять' (аты сэргэБэ баай 'привязать лощадь к коновязи'); cblhblap- (биллэриини сыһыар 'прикрепить объявление'); килиэйдээ- 'заклеить, заклеивать' (конверы килиэйдээ 'заклеить конверт'); туруор- 'ставить, укреплять, устанавливать' (люстраны туруор 'установить люстру'), холбоо- 'соединять, подсоединять' (проводтары холбоо 'соединить проводы', бэрэбинэлэри туруоһунан тыраахтарга холбоо 'бревна присоединить тросом к трактору'); тимэхтэн- 'застегивать, пристегивать' (соннун тимэхтэн 'застегивать пуговицы пальто'); mутmар- (лиистэри скрепканан туттар 'скрепить листы скрепками').

2. Собрать, сосредоточить что-л. в одном месте. Хомуй- 'собрать в одном месте' (түүлээх хомуй ‘собрать пушнину', отон хомуй ‘собрать ягоды'), мус- 'собирать, кого-что-л., в одном месте; складывать в кучу, грудой' (оту мус 'складывать траву', арыыны мус 'складывать масло', онньууру биир сиргэ мус 'собрать игрушки в одном месте'), чөмөхтөө- 'собирать, складывать что-л. в кучу' (кууллары чөмөхтөө 'собирать в кучу кули'), чөмчөхтөө- 'собирать, сгребать что-л. в кучу, складывать грудой' (малы биир сиргэ чөмөхтөө 'собирать вещи в кучу').

3. Глаголы, обозначающие 'собрать, соединить, сложить, составив что-либо', составлять из нескольких однородных предметов одно целое, объединять: хомуй'собрать, набрать, сосредоточить в одном месте, добывая, приобретая, разыскивая (напр., материалы фольклора)' (остуоруйалары хомуй 'собирать сказки'), онор'составить' (словарь онор 'составить словарь'), mahaap- (хомуурунньук таһаap 'издать сборник').

4. Глаголы, со значением 'образовать нечто целое из каких-либо отдельных элементов'. Хомуй- 'собирать, монтировать', 'соединив и скрепив отдельные детали, части, собрать что-л. в одно целое (какой-л. механизм, машину, устройство)' (оборудованиены хомуй 'смонтировать оборудование', генераторы хомуй 'собирать генератор'), тан- 'собрать' (паззлары тан 'собрать паззлы').

5. Созвать или согнать, собрать в одном месте (людей, животных): хомуй'собирать (төрөппүттэри хомуй 'собрать родителей', дьону хомуй 'созвать людей', ынахтары хомуй 'согнать коров'), ыньыр- 'созывать', (до5отторгун ыныр 'собрать друзей', ыалдьыттары ыныр 'созвать гостей'); түмn- 'собирать в одном месте' (нэһилиэк дьонун түмп 'собирать в одном месте жителей наслега').

6. Глаголы, объединенные семантикой 'накапливать, копить, собирать' (прям., и перен.): хомуй- 'собирать' (значок хомуй 'собирать значки'), мус- 'копить' (харчы мунньун 'копить деньги'); xaнam- (баай ханат 'скопить богатство'); коллекциялаа- 'коллекционировать' (фарфоры коллекциялаа 'коллекционировать фарфор'). 
7. Глаголы со значением 'соединив несколько разнородных предметов, приготовить раствор, смесь, сплав, соединять, смешивать': булкуй- 'мешать, смешивать, перемешивать' (кырааскалары булкуй 'смешать краски'), холбоо- (сымыыты бурдукка холбоо 'соединить яйцо с мукой', кыһыл көмүһү алтаны кытта холбоон ууллар 'соединить сплав золота и меди').

8. Глаголы со значением 'связывать кого-л. с кем-л., на основе общности чего-л. (интересов, взглядов и т. п.), сближать, приобщать кого-что-л. к чему-л.': түмүс- 'сплачиваться, объединяться' (үлэһиттэр түмүстүлэр 'рабочие сплочились'), холбоо- (Манна олохтоохтор бары аналлаах миэстэлээхтэр, кыттыгастаахтар. Атын киһини холбооботтор. "Чолбон". Бааһынай, оробуочай Бастарын холбоон, Бардамнык үлэлээн, Баабырыкалары бааралаатылар, Собуоттары субуруттулар. Эллэй).

Глаголы лексико-семантической группы со значением каузации посессивных отношений обозначают ситуации, в которых происходит приобщение объекта к действующему лицу, когда существовавшие до этого раздельно и независимо друг от друга субъект и объект вступают в отношения совместности, владения [2]. Как указывает Э. В. Кузнецова, глаголы приобщения объекта делятся на группы по признаку наличия или отсутствия в данной ситуации еще одного лица.

Глаголы первой группы обозначают приобщение независимого объекта.

1. Базовое значение 'получить в обладание, стать обладателем чего-либо' идентифицирует лексемы: туm- 'получить' (сурук тут 'получить письмо'), bлл- 1. 'приобрести' (билиини ыл 'приобрести знания'), 2. 'брать, покупать' (магазинтан килиэп ыл 'брать хлеб в магазине', киинэђэ билиэт ыл 'купить билет в кино'), өлөр- 'заработать', т.е. (харчы өлөр 'заработать деньги'), хамнастан- 'приобрести работой, трудом'. Дифференциальные значения имеют глаголы: бай- 'разбогатеть, нажиться, наживаться'; дьapblгыр- 'промышлять' (атыынан дьарыгыр 'промышлять торговлей'), бул- 'находить; добыть', т.е. 'приобрести что-либо нужное, необходимое' (наадалаах материалы бул 'найти (приобрести) нужный материал'), атыыblлас- 'приобрести, купить, покупать' (мебель атыылас 'купить мебель') и др.

2. Значением 'приобрести определенным образом' объединяются лексемы: батараактаа- 'батрачить'; наймылас- 'наниматься на работу', хаһаайыстыббалан'сколотить хозяйство, обзавестись хозяйством', умналаа- 'попрошайничать, побираться'.

3. Отдельную микрогруппу составляют глаголы со значением приобретение чего-либо нечестным путем. Основное значение данного понятия передают глагол уор'воровать, красть', былдьаa- 'отнимать'. Дифференциальным признаком 'приобрести что-либо чужое' объединяются глаголы, синонимичные данным глаголам: апчарый'присваивать, прихватывать чужое', кыббын- 'взять без спроса', -талаа 'грабить' и т.д.

Вторая группа глаголов, выражающая ситуацию приобщения объекта, принадлежащего другому лицу (лицам), объединяет лексемы: ыл- 1. 'брать (бэрик ыл 'брать взятки'), 2. взимать, взыскивать (штраф ыл 'брать штраф'), хомуй- 'взимать, собирать (налог хомуй 'собирать налог', дань хомуй 'взимать дань'), атастас- 'менять, обменять, выменять' (хортуоппуйу бурдукка атастас 'обменять картофель на муку'), мэнэйдэс- 'обмениваться', арендалаа- 'арендовать' (залы арендалаа 'арендовать зал'); былдьаa- 'отвоевать, отобрать' (территорияны былдьаа 'отвоевать территорию'); көрдөс- 'попросить' (харчы иэс көрдөс 'попросить деньги в долг').

Значением 'каузировать кого-либо иметь что-либо' идентифицируются глаголы: биэр- 'дать, вручить' (кинигэни биэр 'дать книгу'); анаa- 'выделить, выдать, отдать' (нэһилиэстибэни оболорго анаа 'разделить наследство детям'); бэлэхтээ- 'подарить' (оонньуур бэлэхтээ 'подарить игрушку'); хатақалаa- 'одаривать, баловать' (минньигэһинэн хатақалаа 'баловать сладостями'), нақараадалаa- 'награждать' (орденынан нақараадалаа 'награждать орденом', бириэмийэлээ- премировать' (бастаабыттары бириэмийэлииллэр 'победивших премируют', төннөр- 'вернуть, возвращать, возвратить' (малы төннөр 'возвращать вещь') и др. 
Таким образом, данные глаголы объединены единой семантикой каузации контакта объектов и посессивных отношений. Каждая подгруппа глаголов данных ЛСГ отличается образом действия относительно объектов, т.е. соединять кого-либо с кемлибо, соединять что-либо с чем-либо, соединяться с кем-, чем-либо; приобщение независимого объекта и приобщение объекта, принадлежащего другому лицу (лицам).

1. Кильдибекова Т. А. Структура поля глаголов действия: Учебное пособие / Т. А. Кильдибекова. Уфа: Изд-во Башкирского госун-та, 1983. - 75 с.

2. Кузнецова Э. В. Русские глаголы «приобщения объекта» как функционально-семантический класс слов: автореф. дисс... докт. филол. наук / Э. В. Кузнецова. М., 1974. - 20 с.

3. Потапенко Т.А. Лексико-семантическая характеристика глаголов разрушительного воздействия на объект // Филологические науки. 1983. № 2. - С. 50-56.

4. Усманова М. Г. Функционально-семантическая классификация глаголов башкирского языка: дис. ... доктора филол. наук / М. Г. Усманова. - Уфа, 2002. - 429 с.

5. Чертыкова М Д. Глаголы со значением психической деятельности в хакасском языке: дис. ... доктора филол. наук / М. Д. Чертыкова. - Абакан, 2016. - С 44.

\section{Kolyada N.A. \\ The importance of developing intercultural communication skills in teaching foreign languages}

Southern Federal University

(Russia, Rostov-on-Don)

doi: $10.18411 / \mathrm{lj}-08-2021-100$

\section{Abstract}

The article considers teaching a foreign language as a means of everyday communication with native speakers of another culture. Special attention is paid to crosscultural learning, which contributes to the achievement of cross-cultural communication. The article offers opportunities for developing the abilities and skills of cross-cultural communication with the involvement of the material of linguistic and cultural content, provides examples of exercises for the development and consolidation of cross-cultural communication skills, aimed at the ability to interpret the existing various models of perception of the world, to relate other cultural customs and mores with their behavioral norms.

Keywords: foreign language communication, the concept of communicative learning, linguistic and foreign studies material, culture and language.

\section{Аннотация}

Рассматривается преподавание иностранного языка как средства повседневного общения с носителями другой культуры. Особое внимание уделяется межкультурному обучению, способствующему достижению межкультурной коммуникации. Предлагаются возможности для развития способностей и навыков межкультурного общения с привлечением материала лингвострановедческого содержания, приводятся примеры упражнений для развития и закрепления навыков межкультурного общения, направленные на умение интерпретировать существующие различные модели восприятия мира, соотносить иные культурные обычаи и нравы со своими поведенческими нормами.

Ключевые слова: иноязычная коммуникация, концепция коммуникативного обучения, лингвострановедческий материал, культура и язык.

The Russian methodology of teaching foreign languages is constantly improving and offers many recommendations and guidelines for achieving the goals set. For a long time, the 